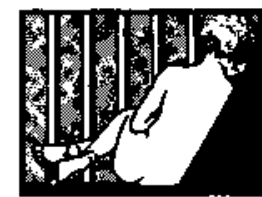

Em 1964, ano do golpe político que deu início à ditadura militar vigente até os anos 80, iniciou-se um empreendimento inćdito na história do atendimento aos menores no País. Pela primeira vez, o governo federal pretendeu traçar orientaçōes unificadas, de alcance nacional. Em $1^{\circ}$ de dezembro de 1964, foi criada a Fundação Nacional do Bem-Estar do Menor (FUNABEM), órgão normativo que tem a finalidade de criar e implementar a "política nacional de bemestar do menor", através da elaboração de "diretrizes políticas e técnicas".

A nivel estadual, foram sendo criadas as FEBEMs, órgãos executivos, responsáveis pela prática das orientações elaboradas pela FUNABEM, através do atendimento direto dos menores. De fato, muitos dos grandes internatos tipo FEBEM já existiamcom outras denominaçōes e apenas foram rebatizados; outros foram construidos com a mesma finalidade de internação e reclusão de menores, embora tenham sido nomeados com eufemismos como "unidades educacionais" ou "terapêuticas". Estes grandes internatos representaram e continuam representando o modelo de atendimento vigente em todo o País, a nível de Estado, nos quais os menores costumam ser classificados em dois grandes grupos: os "infratores" que foram recolhidos na rua pela polícia e julgados pela Justiça, permanecendo sob custódia destas instituiçôes; os "abandonados", cujos pais não possuem condiçōes de criá-los ou são órfāos, sem pais adotivos.

Esta estrutura gigantesca da FUNABEM-FEBEMs nem pode aspirar a atender o número astronômico de menores considerados como "destinatários das açōes da FUNABEM" e ela própria reconhece a sua incapacidade de atingir este objetivo. Um documento oficial, elaborado com o advento da "Nova República", constata: "Embora a economia brasileira tenha avançado significativamente, ocupando o $8^{\circ}$ lugar na escala mundial, vivem atualmente no País cerca

\section{A palavra da FUNABEM}

de 70 milhōes de brasileiros em situação precária. Quanto aos menores de 18 anos, a Fundação IBGE calcula em cerca de 36 milhöes os que vivem ern situação precária, ou seja, aqueles cujos pais percebem menos de dois salários mínimos. Assim sendo, mesmo que os dados do IBGE fossem exagerados como alegam alguns, e caso a internação de crianças e jovens de baixa renda fosse a solução, esta seria inexequível, pois, além de desumano, internar muitos milhöes de menores seria economicamente inviável" ("FUNABEM 23 anos", 1987, p. 4 e 5).

Sendo totalmente inviável atender à maioria dos menores "em situaçāo de risco", a quantos a FUNABEM atende de fato? Eis a resposta: "No triênio 1987-1989, a entidade dará prioridade absoluta aos mais variados tipos de apoio às crianças e jovens em situação de risco pessoal e social, de 7 a 18 anos, acrescidos daqueles de 0 a 6 anos que se encontrarem sob tutela judicial. Calcula-se que o número dessas crianças e jovens esteja $\mathrm{em}$ torno de 7 milhões" ("FUNABEM 23 anos", 1987, p.6).

Em outro documento oficial, temos os seguintes dados numéricos: "A FUNABEM responde hoje (em 1986) pelo atendimento direto, em seus estabelecimentos, por cerca de 3.000 crianças e adolescentes. No Brasil como um todo (supomos que se trata de unidades das FEBEMs - nota da Redação), o número de crianças ditas 'infratores' é de apenas 5.972. O custo de cada uma das crianças e adolescentes entregues à guarda de estabelecimentos da FUNABEM é calculado, em média, em 4 salários mínimos por mês" ("Alternativas do atendimento e a desestatização da questão do menor", FUNABEM, 1987 , p. 18 e 19$)$.

Diante desta realidade numérica, como estão sendo definidos os planos da FUNABEM para 1988? A presidente desta entidade, Marina Bandeira, responde: "1988 será, sem dúvida alguma, um ano em que todos nós da
FUNABEM teremos oportunidade de solidificar o processo de mudança dos métodos, do tipo de atendimento prestado até agora aos menores em dificuldade no Brasil. A experiência no passado nos mostra que as formas antigas, como o internamento indiscriminado de menores e a centralização de recursos neste ou naquele órgão estadual, não deram certo. Em 1986, iniciamos o processo de municipalização, com a descentralização de recursos técnicos e financeiros através do apoio maior às experiências de apoio ao menor que estão dando certo nos mais longínquos e diferentes pontos do País. Em 1987, a descentralização continuou e em 88 vamos acelerar esse processo, procurando, cada vez mais, firmar contratos e convênios diretamente com entidades sociais particulares, prefeituras e organismos públicos que comprovem eficiência no atendimento a crianças e jovens em dificuldade. Para isso vamos fortalecer ainda mais os escritórios de Representação da FUNABEM nos Estados, para que as equipes técnicas tenham condiçōes de acompanhar o aumento de trabalho".

E quais são os recursos disponíveis da FUNABEM para 1988? A presidente da entidade responde: " $O$ ano de 1987 foi atípico. Trabalhamos no ano passado com um orçamento que chegou a aproximadamente 6 bithōes e 500 milhões de cruzados, ou seja, $1.000 \%$ a mais do que em 86 . Se for descontada a inflação, verificaremos que o crescimento real dos recursos da FUNABEM chegou a $250 \%$. Assim, passamos de uma participação histórica de $0,24 \%$ no orçamento global do Ministério da Previdência Social, para algo $\mathrm{em}$ torno de $1,2 \%$. 0 orçamento de 1988 ainda está em fase de planejamento, mas o Ministro Renato Archer já me garantiu um crescimento real de $20 \%$ em relação ao ano passado".

Com estes recursos, os projetos prioritários estão definidos assim: "A FUNABEM dará prioridade a projetos que contemplem crianças e jovens 
de 7 a 18 anos em situação de risco pessoal e social, como aqueles explorados no mundo do trabalho, os envolvidos com tráfico de drogas, os prostituídos, os infratores, enfim, menores que vivem na miséria absoluta. Nesse contexto, vamos priorizar, entre outros, o Programa de Apoio aos Juizados de Menores, para dar melhores condições de trabalho aos juízes em todos os pontos do País; o Projeto Rural para fixar o menor e sua família no campo; o Programa Ocupação de Fronteiras, que está sendo desenvolvido juntamente com outros órgãos do SINPAS e as Forças Armadas, para proporcionar melhores condiçōes de vida às populaçōes que habitam as regiões de fronteiras do Norte, do Centro-Oeste e do Sul; a reformulação do atendimento direto no Rio de Janeiro que vai buscar novos caminhos que poderão ser úteis e sirvam como pistas para diferentes soluções no restante do Brasil; o Projeto Esporte que visa à socialização do jovem através da prática desportiva e o Projeto Educação Não Formal que busca incentivar o desenvolvi- mento de novas formas de educação, alternativas às já existentes. E também prioridade em 88 continuar ouvindo cada vez mais as aspiraçōes dos municípios, respeitando a identidade de cada comunidade".

Como serão apoiadas e incentivadas as açōes municipais? A presidente da FUNABEM prosseguiu respondendo: "Como já salientei, a prioridade será para as açōes com predominância do atendimento a nível comunitário, o envolvimento das Prefeituras, a assistência ao menor infrator em regime aberto e outras alternativas que. evitem internamento, como os lares substitutos, as creches domiciliares, e $o$ incentivo às propostas de profissionalização e geração de renda, a methoria das condições de trabalho de entidades e grupos comunitários que amparam o menor, a implantação de modalidades alternativas de profissionalização dos jovens portadores de deficiência e a melhoria das condiçōes de infra-estrutura dos Juizados de Menores e Delegacias de Proteção ao Menor em todo o País, para permitir melhor qualidade no desempenho de suas funçöes".

Apesar de a retórica oficial apontar mudanças como, por exemplo, a de que "está superando o papel de mera repassadora de recursos" "Compromissos políticos e diretrizes técnicas: 1987-1989", p. 22), esta mudança não parece estar sendo posta em prática, de forma concreta. A grande maioria das FEBEMs, espalhadas por todo o País, continua dependendo diretamente do repasse de verbas da FUNABEM. Esta dependência de verbas é total nas FEBEMs de todos os Estados do Nordeste; sem este repasse, elas simplesmente ficariam sem qualquer orçamento e abririam falência administrativa. Em maior ou menor proporção, as FEBEMs de outros Estados da Federação também dependem diretamente deste repasse de verbas da FUNABEM. A única exceção neste quadro é a FEBEM-São Paulo que recebe uma verba irrisória da FUNABEM, a qual nem chega a contabilizar $1 \%$ do orçamento total desta unidade, pois depende da verba destinada pelo governo estadual.

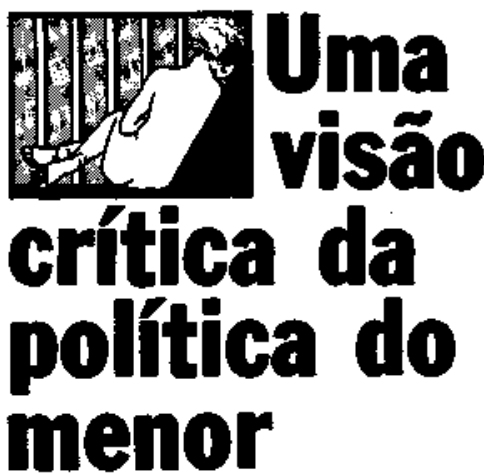

Além de situar como e porque as politicas oficiais de atendimento aos menores não conseguem beneficiar este segmento da populaçäo brasileira, o psicólogo Benedito Adalberto Boletta de Oliveira, com base en quase 10 anos de experiéncia como técnico em orgãos de atendimento de menores, sugere também algumas alternativas de intervençäo tanto em termos de atendimento direto quanto de compreensão dos problemas vividos pelos menores num contexto estrutural de pauperização da população brasileira. Eis as suas opiniōes:

Para fazer uma análise das políticas de atendimento à menoridade num país como o nosso, é importante 